\title{
On gas-friction, and on the velocity of electricity in the electric current
}

\section{Prof. Ludwig Boltzmann}

To cite this article: Prof. Ludwig Boltzmann (1880) On gas-friction, and on the velocity of electricity in the electric current, Philosophical Magazine Series 5, 9:56, 307-309, DOI: $10.1080 / 14786448008626844$

To link to this article: http://dx.doi.org/10.1080/14786448008626844

册 Published online: 28 Apr 2009.

Submit your article to this journal $\lceil\pi$

Џ Article views: 6

Q View related articles $\asymp$ 
From these numbers I draw the following conclusions :-

1. The old theory of the freezing of lakes, which assumes a progressive cooling of the whole mass down to $4^{\circ}$, and then a further lowering of the temperature of the superficial layers stratified from $0^{\circ}$ to $4^{\circ}$ according to the order of their densities, is perfectly correct.

2. The penetration of the cold into the upper layers may descend to a depth of 110 metres (Zurich).

3. It was in consequence of its comparative shallowness that Loch Lomond did not exhibit to Mr. Buchanan the temperature of $4^{\circ}$ in its bottom layers.

4. The penetration of cold into the upper layers takes place progressively and very gradually. The curve which can be drawn from my numbers from the Lake of Zurich presents neither leaps nor jerks; it is altogther analogous to the curves of superficial heating of a lake in summer. This, it seems to me, is quite sufficient to put aside the supposition that the cooling, which penetrates so deeply, takes place either by way of thermal convection or by mechanical mixture under the action of waves and currents-with the exception, perhaps, of the upper layer of from 5 to 10 metres thickness.

Must this penetration of cold be attributed to phenomena of conductivity, or to phenomena of radiation, either of the water itself or of the soil through the water? The experiments have not supplied me with any elements for answering this question.

5 . On comparing the two series of soundings made in the Lake of Morat, separated by an interval of forty days, I find that the mean temperature remained exactly the same. Therefore the layer of ice absolutely stopped the cooling of the water, and the action of the exterior cold was all expended in increasing the thickness of the ice.

6. During these forty days the water of the Lake of Morat beneath the ice underwent an equalization of temperature; the colder upper layers were warmed a little, while the warmer bottom layers were cooled; but we are still very far from finding complete uniformity of temperature in the entire depth of the lake on the 1st of February.-Comptes Rendus de l'Acad. des Sciences, Feb. 16, 1880.

\section{ON GAS-FRICTION, AND ON THE VELOCITY OF ELEC'TRICITY IN}

THE ELECTRIC CURRENT. BY PROF. LUDWIG BOLTZMANN.

In a memoir entitled "To the Theory of Gas-friction," the relative velocity and its longitude and latitude with respect to the relocity of one of the molecules as axis, and to the plane of the velocities of both molecules as first meridian, are introduced as integration-variables; and thereby the equation for the distribution of velocities in a moved gas is simplified. Here the velocities meant are everywhere those before impact. The determination of the coefficient of friction by the development of a series, exact account being taken of the distribution of velocities, is then encountered by no difficulty. 
In addition, M. Boltzmann remarks that the magnetizing of a ring can be most easily calculated by introducing Carl Neumann's coordinates, and that the absolute value of the velocity of the electricity in a current can be calculated from E. H. Hall's recently published uncommonly interesting experiments. If the gold leaf employed by Hall, of the length $l$ and breadth $b$, is in a homogeneous magnetic field of the intensity $m$ (measured in absolute Gauss measure), the electromagnetic force which tends to impel it perpendicular to the lines of magnetic force has the intensity

$$
k=m l \mathbf{J}_{m}=\frac{m t_{\mathrm{J}}}{v},
$$

in which $J_{m}$ is the intensity of the current passing through the gold leaf in the direction of its Iength (in magnetic measure), $J_{e}$ is the same current-intensity measured in Weber's electrostatic or mecha-

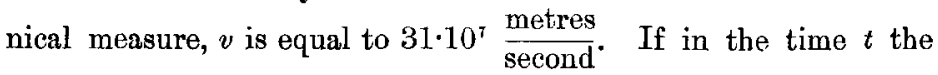
quantity of electricity $e$ passes through the cross section of the gold leaf with the velocity $e$, then is $\mathrm{J}_{e}=\frac{e}{t}=\frac{e c}{l}$, and hence $k=\frac{m e c}{v}$. If now at two places in a conductor, separated by the distance $b$, the difference of potential $p$ prevails, in its interior the force $\frac{p}{b}$ acts upon the unit amount of electricity, upon the amount $e$ the force $\frac{p e}{b}$. Hence, if the force above denoted by $k$ itself acts upon the movable electricities in the gold leaf, and the potential-difference thereby produced between the two extremities of the gold leaf be denoted by $p$, then is $k=\frac{p e}{b}, p=\frac{k b}{e}=\frac{m b c}{v}$. Now let the two extremities of the gold leaf be connected with a galvanometer. The total resistance of this circuit (gold leaf, galvanometer, and conducting-wires) shall be denoted by $w$, and $i$ shall denote the current-intensity produced therein by the magnet, while again the index $m$ signifies magnetic, the index $e$ mechanical measure of the current. Then is $i_{e}=\frac{p}{v_{e}}=\frac{m b c}{v w_{e}^{\prime \prime}}, i_{m}=\frac{m b c}{w_{m}}$, from which it follows that $c=\frac{i_{m} v_{m}}{m b}$. From this formula the absolute velocity $c$ of the electricity in the current $J$ can be determined. It is exactly equal to the velocity with which a wire of length $b$ must be moved, perpendicular to itself, through the magnetic field, in order that it may generate the current $i$ in a circuit of resistance $w$. In this the wire is supposed to be parallel to the length, the direction of its motion parallel to the width, of the gold leaf. If we put $i_{m} w_{m}=e_{m}$, then $e_{m}$ is the electromotive force, in magnetic measure, which would produce in the same circuit the same current $i_{m}$. Its measurement suffices for the calculation of $c$. In order to obtain the general theory of Hall's phenomenon, the equations constructed by Kirch- 
hoff, Weber, Helmholtz, Maxwell, Stefan, \&c. for the motion of electricity in material conductors must be extended by adding to the electrostatic potential and the action of induction a term expressing the electrodynamic action, and easily calculated when the eurrent in the volume-element that acts and is acted on is resolved into three components at right angles to one another and their reciprocal action calculated according to an electrodynamic law (Ampère's for instance).-Kaiserliche Akademie der Wissenschaften in Wien, muth.-naturw. Classe, Jan. 15, 1880, pp. 11-13.

RESEARCHES ON THE RELATIVE INTENSITY OF THE SPECTRAL LINES OF HYDROGEN AND NITROGEN IN REGARD TO THE CONSTITUTION OF NEBULA. BY CH. FIEVEZ, ASSISTANT ASTRONOMER AT THE ROYAL OBSERVATORY AT BRUSSELS.

Huggins's observations * having shown that the spectrum of the nebulæ $37 \mathrm{H}$ IV. Draconis, 73HIV. Cygni, and some others consisted of a few bright lines, one of which, brighter than the others, coincides with a nitrogen-line, and another, finer, corresponds with the line $\mathrm{F}$ of hydrogen, he was led to investigate whether the complicated spectrum of nitrogen might not be simplified by extinction $\uparrow$.

He remarked that, by causing the induction-spark to spring between platinum electrodes placed before the objective of a telescope, only one line of nitrogen was visible in the spectroscope applied to the ocular extremity.

Afterwards, examining the spectrum of nitrogen with a spectroscope having a prism of $60^{\circ}$, and placing near the eye a neutraltint prism corrected for refraction and possessing equal absorptive power for all parts of the spectrum, he saw that the two groups of nitrogen-lines in the orange were nearly extinguished, while the lines in the green were very bright. And on employing a small direct-vision spectroscope, Huggins found it possible, by increasing the distance between the instrument and the spark, to obtain a position in which the double line in the green (Plücker's group IV.) + coincident with that of the nebula was alone visible. The spectrum of the spark in nitrogen then resembled that of the nebula.

Huggins's researches do not appear to have been carried further in this direction; nevertheless he believes that, if the spectrum of hydrogen were reduced in intensity, the line $\mathbf{F}$, which corresponds with that of the nebula, would alone remain visible after the line $C$ and the other more refrangible ones had become too faint to affect the eye.

The verification of this hypothesis is connected with a very important question, viz. " Do the lines of the spectrum of a nebula represent the total light emitted by that body? or are they merely

* " Un the Spectra of some of the Nebulæ," Philosophical Transactions, 1864, p. 437.

+ Phil. Trans. 1868, p. 542.

\pm "On the Spectra of Ignited Gases," Phil. Trans. 1865, plate ii.

Plitl. Mag. S. 5. Vol. 9. No. 56. April 1880. 